Arq. Bras. Med. Vet. Zootec., v.60, n.5, p.1227-1233, 2008

\title{
Alimentação de leitoas pré-púberes com dietas contendo zearalenona
}

[Feeding of pre-pubertal gilts with diets containing zearalenone]

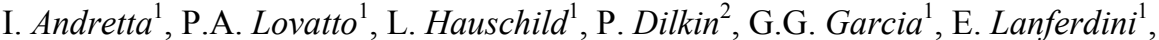 \\ N.C. Cavazini ${ }^{1}$, C.A. Mallmann ${ }^{2}$ \\ ${ }^{1}$ Departamento de Zootecnia - UFSM \\ 97105-900 - Santa Maria, RS \\ ${ }^{2}$ Laboratório de Análises Micotoxicológicas - UFSM - Santa Maria, RS
}

\begin{abstract}
RESUMO
O desempenho, o peso de alguns órgãos e a morfologia vulvar de leitoas pré-púberes, alimentadas por 28 dias com dietas contendo zearalenona, foram avaliados. O delineamento experimental utilizado foi inteiramente ao acaso, com dois tratamentos, dieta controle (DC) e dieta controle $+2 \mathrm{mg} \mathrm{kg}^{-1} \mathrm{de}$ zearalenona (DZ), e seis repetições cada. Não houve diferença $(\mathrm{P}>0,05)$ entre os tratamentos para consumo médio diário de ração $(1,24 \times 1,19 \mathrm{~kg})$, ganho médio diário de peso $(0,68 \times 0,71 \mathrm{~kg})$, conversão alimentar $(1,86 \times 1,71)$ e peso vivo (PV); $(30,9 \times 30,4 \mathrm{~kg})$. A zearalenona não alterou $(\mathrm{P}>0,05)$ os pesos absoluto e relativo do coração ( 137 x $141 \mathrm{~g}$ e 0,45 x $0,45 \%$ PV), fígado $(699$ x $699 \mathrm{~g}$ e 2,31 x $2,26 \% \mathrm{PV})$, rins $(47 \times 49 \mathrm{~g}$ e $0,15 \times 0,16 \% \mathrm{PV})$ e baço $(166 \times 171 \mathrm{~g}$ e $0,55 \times 0,55 \% \mathrm{PV})$. Houve aumento $(\mathrm{P}<0,05)$ no comprimento $(17 \times 27 \mathrm{~cm})$ e no peso $(23 \times 157 \mathrm{~g}$ e $0,07 \times 0,51 \% \mathrm{PV})$ do trato reprodutivo das leitoas do grupo DZ. O volume vulvar ao final do período foi $820 \%$ maior $(\mathrm{P}<0,05)$ nos animais alimentados com zearalenona $\left(941 \times 8658 \mathrm{~mm}^{3} / \mathrm{kgPV}^{0,6}\right)$. Os resultados indicam que em suínos a zearalenona e seus metabólitos possuem atividade estrogênica, mas não interferem no desempenho dos animais.
\end{abstract}

Palavras-chave: suíno, desempenho, hiperestrogenismo, micotoxina

\begin{abstract}
The performance, the weights of some organs, and the vulvae morphology in pre-pubertal gilts fed diets containing zearalenone were evaluated during 28 days. The experimental design was completely randomized with two treatments (control diet, $Z D$ - control diet $+2 m g \mathrm{~kg}^{-1}$ of zearalenone) and six replications of each were done. No differences $(P>0.05)$ between treatments for daily feed intake $(1.24 x$ $1.19 \mathrm{~kg})$, average daily gain $(0.68 \times 0.71 \mathrm{~kg})$, feed conversion ratio $(1.86 \times 1.71)$, and live weight $(30.9 \times$ $30.4 \mathrm{~kg})$ were observed. Zearalenone did not change $(P>0.05)$ the absolute and relative weights of heart $(137 \times 141 \mathrm{~g}$ and $0.45 \times 0.45 \% \mathrm{BW})$, liver $(699 \times 699 \mathrm{~g}$ and $2.31 \times 2.26 \% \mathrm{BW})$, kidneys $(47 \times 49 \mathrm{~g}$ and $0.15 \times$ $0.16 \% \mathrm{BW}$ ), and spleen $(166 \times 171 \mathrm{~g}$ and $0.55 \times 0.55 \% \mathrm{BW})$. However, zearalenone increased $(P<0.05)$ the length $(17 \times 27 \mathrm{~cm})$ and weight $(23 \times 157 \mathrm{~g}$ and $0.07 \times 0.51 \% \mathrm{BW})$ of the reproductive tract. The final vulvae volume was $820 \%$ larger $(P<0.05)$ in gilts fed diets containing zearalenone than those fed control diet $\left(941 \times 8658 \mathrm{~mm}^{3} / \mathrm{kgBW}^{0.6}\right)$. Results suggested that zearalenone and its metabolites have an estrogenic activity in pigs without changing the animal performance.
\end{abstract}

Keywords: pig, performance, hyperestrogenism, mycotoxin

\section{INTRODUÇÃO}

Micotoxinas são metabólitos secundários tóxicos produzidos por fungos filamentosos com alta prevalência em matérias-primas destinadas à alimentação animal. A zearalenona (ZEA) é uma micotoxina estrogênica não esteróide, quimicamente descrita como uma lactona do ácido fenólico resorcílico (Gaumy et al., 2001). A ZEA é produzida por várias espécies de fungos

Recebido em 8 de dezembro de 2007

Aceito em 8 de setembro de 2008

E-mail: ines_andretta@mail.ufsm.br 
do gênero Fusarium, principalmente $F$. culmorum, $F$. graminearum e $F$. crookwellense. Estas espécies colonizam cereais, especialmente em estações com umidade elevada e temperatura amena. Dessa forma, a ZEA ocorre naturalmente em cereais como trigo, cevada, arroz e milho, em vários países (Placinta et al., 1999).

Os efeitos tóxicos da ZEA estão associados principalmente a complicações nas funções reprodutivas, demonstrando atividade anabólica e estrogênica em várias espécies (Diekman e Green, 1992). Entre os animais domésticos, os suínos são os mais sensíveis à presença da micotoxina, podendo apresentar sinais clínicos de intoxicação a partir de $50 \mu \mathrm{g} \mathrm{kg}^{-1}$ de ZEA nas dietas (Bauer et al., 1987).

Após a ingestão, a ZEA é rapidamente absorvida pelas células do trato gastrintestinal (Ramos et al., 1996), sendo a absorção estimada em 85\% nos monogástricos (Malekinejad et al., 2005). A flexibilidade na conformação espacial da ZEA e dos produtos de sua biotransformação hepática permite a competição com o $17 \beta$-estradiol por receptores estrogênicos das células uterinas, hipotalâmicas, hipofisárias e das glândulas mamárias (Kuiper-Goodman et al., 1987). Essa interação incrementa a síntese protéica e manifesta-se principalmente pelo aumento de volume nos tecidos do trato reprodutivo e em quadros caracterizados de vulvovaginite. Também pode ser observada redução na taxa de concepção acompanhada de repetição de cio, nascimento de leitões fracos e natimortos e, muitas vezes, surtos da síndrome dos membros abertos (Malekinejad et al., 2006).

Embora pouco explorados, os efeitos tóxicos da ZEA interferem na síntese lipídica e protéica dos animais (Szkudelska, 2002; Abid-Essefi et al., 2004). Assim, suínos poderiam apresentar alterações no seu desenvolvimento quando expostos à micotoxina. Este trabalho foi realizado com os objetivos de estudar as respostas de desempenho de leitoas pré-púberes alimentadas com dietas contendo ZEA, e avaliar as possíveis alterações na morfologia vulvar e em alguns órgãos.

\section{MATERIAL E MÉTODOS}

Foram utilizadas 12 leitoas pré-púberes, geneticamente homogêneas, com peso médio inicial de $11,5 \mathrm{~kg}$, oriundas de cruzamento industrial e desmamadas aos 21 dias de idade. Os animais foram alojados individualmente em baias elevadas $(1,50 \times 1,37 \times 0,80 \mathrm{~m})$, equipadas com comedouro semi-automático e bebedouro tipo concha. A temperatura da sala foi mantida na zona de conforto térmico para a fase.

O delineamento experimental foi o inteiramente ao acaso, com dois tratamentos, dieta controle e dieta controle $+2 \mathrm{mg} \mathrm{kg}^{-1}$ de ZEA, e de seis repetições cada, sendo o animal a unidade experimental. As dietas isonutritivas foram elaboradas com milho, farelo de soja e premix vitamínico-mineral. A formulação das dietas seguiu o modelo e as recomendações nutricionais do NRC (Nutrient..., 1998). O fornecimento da ração foi à vontade, e os animais tiveram livre acesso à água. $\mathrm{O}$ período experimental foi de 28 dias.

A ZEA foi produzida em frascos tipo Erlenmeyer. Os esporos do fungo foram produzidos em ágar batata cultivados a $25^{\circ} \mathrm{C}$ por cinco dias. Após o período, os esporos foram lavados com água estéril e solubilizados. Foi aplicado $1 \mathrm{ml}$ dessa solução no material de cultura. A incubação compreendeu um período de duas semanas com temperatura de $28^{\circ} \mathrm{C}$ seguido de outro período com temperatura de $15^{\circ} \mathrm{C}$. O material foi seco, triturado, quantificado e estocado a $-4^{\circ} \mathrm{C}$ até a mistura nas dietas. A quantificação da ZEA nos ingredientes e nas rações foi realizada por cromatografia líquida de alta eficiência, com limite de quantificação de $12 \mu \mathrm{g} \mathrm{kg}^{-1}$ e coeficiente de recuperação de $89 \%$. $\mathrm{O}$ milho e o farelo de soja utilizados na formulação não apresentaram concentração para ZEA quando analisados neste método. Após adição do material de cultivo de ZEA na ração, esta foi analisada para verificar se os níveis estavam dentro do desejado. A presença de outras micotoxinas, como aflatoxinas, fumonisinas e tricotecenos (deoxinivalenol, diacetoxicirpenol e toxina $\mathrm{T}-2$ ) também foi avaliada.

As variáveis de desempenho foram o consumo de ração e o ganho de peso (por pesagens semanais). A conversão alimentar foi estimada a partir das variáveis anteriores. A morfologia vulvar das leitoas foi acompanhada por medidas das distâncias vertical, horizontal e de profundidade realizadas a cada três dias com 
paquímetro. O volume vulvar foi estimado pela multiplicação das três medidas anteriores e ajustado ao peso metabólico $\left(\mathrm{PV}^{0,6}\right)$ médio para cada semana. Ao final do experimento, todos os animais foram abatidos e eviscerados, respeitando-se seis horas de jejum alimentar e utilizando-se método elétrico de insensibilização. Coração, fígado, rins e baço foram retirados e pesados individualmente. $\mathrm{O}$ trato reprodutivo foi pesado e medido longitudinalmente (da porção cranial do corno uterino mais longo à extremidade mais distal da vulva). Os dados obtidos foram submetidos à análise de variância pelo procedimento General Linear Model (GLM). As análises estatísticas foram realizadas com auxílio do programa Minitab (Mackenzie e Goldman, 1999).

\section{RESULTADOS E DISCUSSÃO}

Os resultados de desempenho dos animais são apresentados na Tab. 1. A inclusão de ZEA na dieta não alterou $(\mathrm{P}>0,05)$ o consumo de ração, a conversão alimentar, o ganho de peso e o peso vivo dos animais. Isso pode ser explicado porque, nessa concentração, a ZEA não altera a digestibilidade das dietas e os metabolismos protéico e energético de suínos (Hauschild et al., 2007). A exposição oral a doses mais altas de ZEA (10mg kg-1) também não influenciou a conversão alimentar e o ganho de peso de leitoas pré-púberes (Green et al., 1990).

Tabela 1. Desempenho de leitoas alimentadas com dietas contendo ou não $2 \mathrm{mg} \mathrm{kg}^{-1}$ de zearalenona

\begin{tabular}{cccccc}
\hline Variável & Período (dias) & Controle & Zearalenona & DPR & P \\
\hline & $1-7$ & 1,00 & 0,97 & 0,10 & 0,65 \\
Consumo de ração, kg/dia & $8-14$ & 1,01 & 1,03 & 0,13 & 0,71 \\
& $15-21$ & 1,32 & 1,26 & 0,22 & 0,69 \\
& $22-28$ & 1,63 & 1,48 & 0,10 & 0,06 \\
& $1-28$ & 1,24 & 1,19 & 0,10 & 0,47 \\
\hline \multirow{3}{*}{ Ganho de peso, kg/dia } & $1-07$ & 0,51 & 0,56 & 0,09 & 0,45 \\
& $8-14$ & 0,69 & 0,71 & 0,13 & 0,78 \\
& $15-21$ & 0,80 & 0,82 & 0,06 & 0,62 \\
Conversão alimentar & $22-28$ & 0,70 & 0,75 & 0,06 & 0,32 \\
& $1-28$ & 0,68 & 0,71 & 0,03 & 0,17 \\
\hline & $1-07$ & 1,96 & 1,78 & 0,28 & 0,32 \\
& $8-14$ & 1,49 & 1,47 & 0,17 & 0,87 \\
& $15-21$ & 1,64 & 1,56 & 0,29 & 0,67 \\
& $22-28$ & 2,36 & 2,01 & 0,26 & 0,07 \\
& $1-28$ & 1,86 & 1,71 & 0,16 & 0,15 \\
\hline
\end{tabular}

DPR: desvio-padrão residual; P: probabilidade.

Algumas alterações nos metabolismos protéico e energético foram descritas em ratos alimentados com dietas contendo níveis elevados de ZEA (Nogowski, 1996; Szkudelska, 2002). Devido à semelhança fisiológica dessa espécie com os suínos, alguns efeitos no metabolismo poderiam ser esperados quando da exposição alimentar a altas concentrações de ZEA. Contudo, o estágio de desenvolvimento dos animais (crescimento, maturidade) pode interferir nesse processo. A influência da ZEA no metabolismo lipídico de animais em crescimento pode ser insignificante devido à baixa deposição lipídica no período. Já a interferência da ZEA na síntese protéica pode evidenciar mecanismos adicionais de toxidade, como os danos oxidativos (Abid-Essefi et al., 2004). Esses efeitos, contudo, não foram extrapolados para níveis menos agregados no organismo dos suínos, como o desempenho.

Estudos relativos às propriedades mutagênicas, carcinogênicas e teratogênicas da ZEA são ainda 
antagônicos. Porém, a atividade estrogênica por si só pode não explicar os diversos, e aparentemente adversos, efeitos da ZEA (AbidEssefi et al., 2004). Outros mecanismos, apesar de ainda pouco conhecidos, também poderiam influenciar o desempenho dos animais.

É preciso considerar ainda que, em contaminações naturais, a presença de ZEA está geralmente associada a outras fusariotoxinas, como as fumonisinas e os tricotecenos. Nessas condições, pode haver redução no consumo e no ganho de peso das leitoas (Doll et al., 2005), sendo os efeitos negativos no desempenho dos animais associados principalmente à presença dos tricotecenos nas dietas. O uso de ZEA produzida em laboratório (portanto, sem a presença de outras fusariotoxinas) pode, em parte, explicar os resultados observados neste trabalho.

As avaliações dos órgãos são apresentadas na Tab. 2. Não foram observadas diferenças $(\mathrm{P}>0,05)$ entre o grupo-controle e o alimentado com dieta contendo ZEA para os pesos absolutos e relativos de coração, fígado, rins e baço. Porém, a presença de ZEA na dieta aumentou $(\mathrm{P}<0,05)$ em $590 \%$ o peso absoluto e em $614 \%$ o peso relativo do trato reprodutivo. O comprimento do aparelho reprodutivo também foi influenciado $(\mathrm{P}<0,05)$ pelo consumo de $\mathrm{ZEA}$, sendo o aumento de $63 \%$ em relação ao grupocontrole. Segundo Doll et al. (2004), o aumento do peso uterino em leitoas pode ser observado já em concentrações de $0,15 \mathrm{mg} \mathrm{kg}^{-1}$ de ZEA nas dietas.

Tabela 2. Características de órgãos de leitoas alimentadas com dietas contendo ou não $2 \mathrm{mg} \mathrm{kg}^{-1} \mathrm{de}$ zearalenona

\begin{tabular}{lcrrr}
\hline \multicolumn{1}{c}{ Variável } & Controle & Zearalenona & DPR & P \\
\hline Trato reprodutivo & & & & \\
Peso, g & 22,8 & 157,2 & 21,4 & $<0,01$ \\
Peso, \% PV & 0,07 & 0,50 & 0,06 & $<0,01$ \\
Comprimento, cm & 16,7 & 27,2 & 2,2 & $<0,01$ \\
Coração & & & & \\
Peso, g & 137,5 & 140,7 & 13,7 & 0,71 \\
Peso, \% PV & 0,45 & 0,45 & 0,05 & 1,00 \\
Fígado & & & & \\
Peso, g & 699,3 & 698,7 & 66,8 & 0,99 \\
Peso, \% PV & 2,31 & 2,26 & 0,19 & 0,71 \\
Baço & & & & \\
Peso, g & 47,2 & 49,5 & 5,9 & 0,53 \\
Peso, \% PV & 0,15 & 0,16 & 0,01 & 0,36 \\
Rins & & & & \\
Peso, g & 165,8 & 171,2 & 22,5 & 0,70 \\
Peso, \% PV & 0,55 & 0,55 & 0,07 & 0,88 \\
\hline
\end{tabular}

DPR: desvio-padrão residual, P: probabilidade.

A evolução do volume vulvar é apresentada na Fig. 1. Foi observada diferença $(\mathrm{P}<0,05)$ entre os tratamentos quanto ao volume vulvar, desde a primeira semana de consumo de dieta com ZEA. Ao final do período experimental, o volume vulvar por unidade de peso metabólico foi $820 \%$ maior $(\mathrm{P}<0,05)$ nas leitoas alimentadas com dieta contendo ZEA em relação às da dieta-controle (Fig. 2).

Estes resultados confirmam as manifestações estrogênicas da ZEA, que em geral são bastante pronunciadas em fêmeas suínas pré-púberes (Malekinejad et al., 2006). Em trabalho semelhante, foi observado aumento no volume vulvar de leitoas alimentadas com dietas contendo $2 \mathrm{mg} \mathrm{kg}^{-1}$ de ZEA após uma semana de consumo (Rainey et al., 1990). Em concentrações mais elevadas (de $10 \mathrm{mg} \mathrm{kg}^{-1}$ de ZEA), os sinais de hiperestrogenismo são percebidos após três dias de consumo (Green et al., 1990). Devido ao aumento rápido do volume vulvar observado neste estudo e em outros relatos de contaminação de dietas com ZEA, o monitoramento desse órgão pode ser uma ferramenta importante para avaliar a atividade da micotoxina nos animais. 


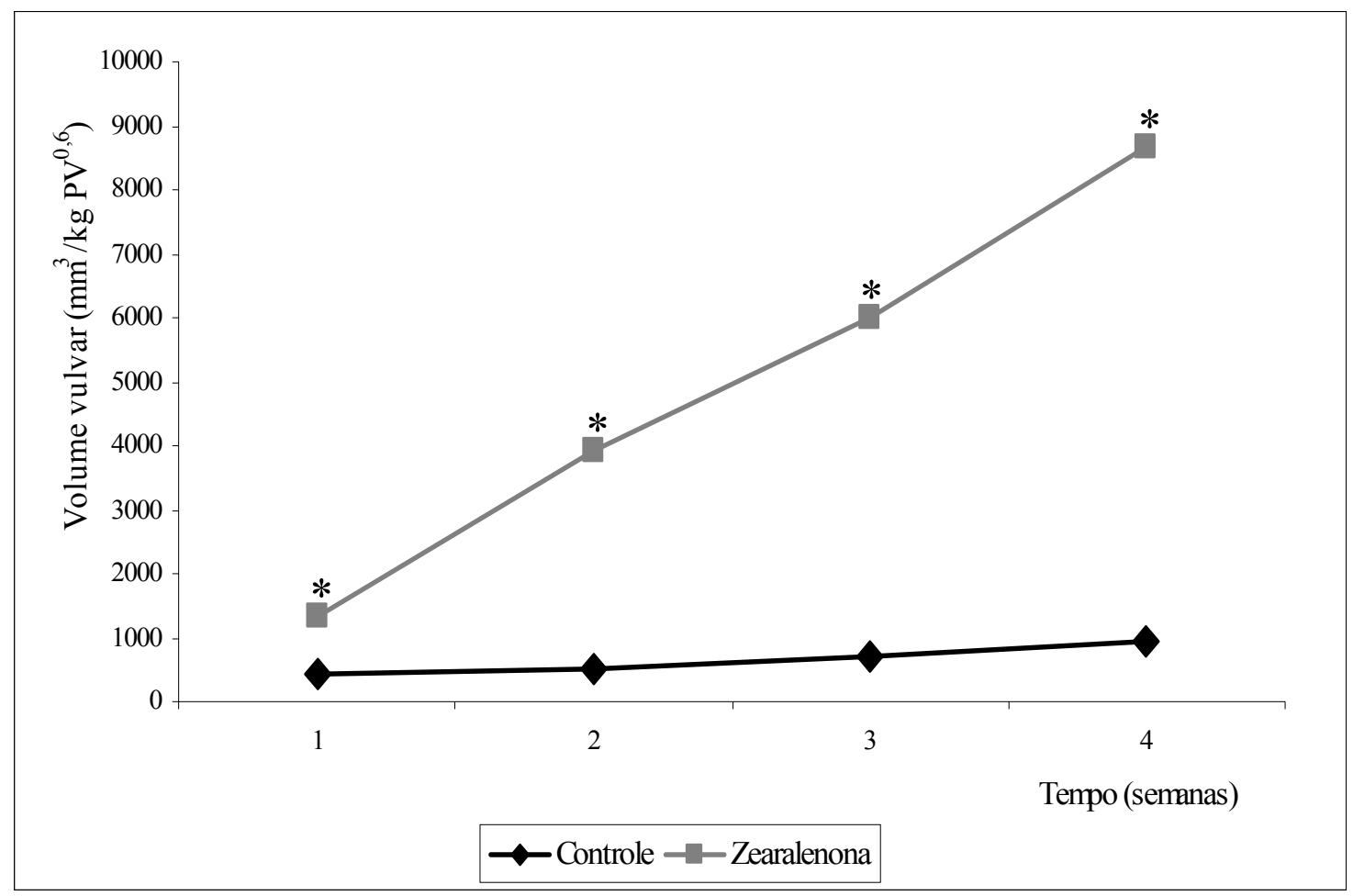

Figura 1. Volume vulvar ajustado ao peso metabólico de leitoas alimentadas com dietas contendo ou não $2 \mathrm{mg} \mathrm{kg}^{-1}$ de zearalenona.

- Diferem estatisticamente $(\mathrm{P}<0,05)$.

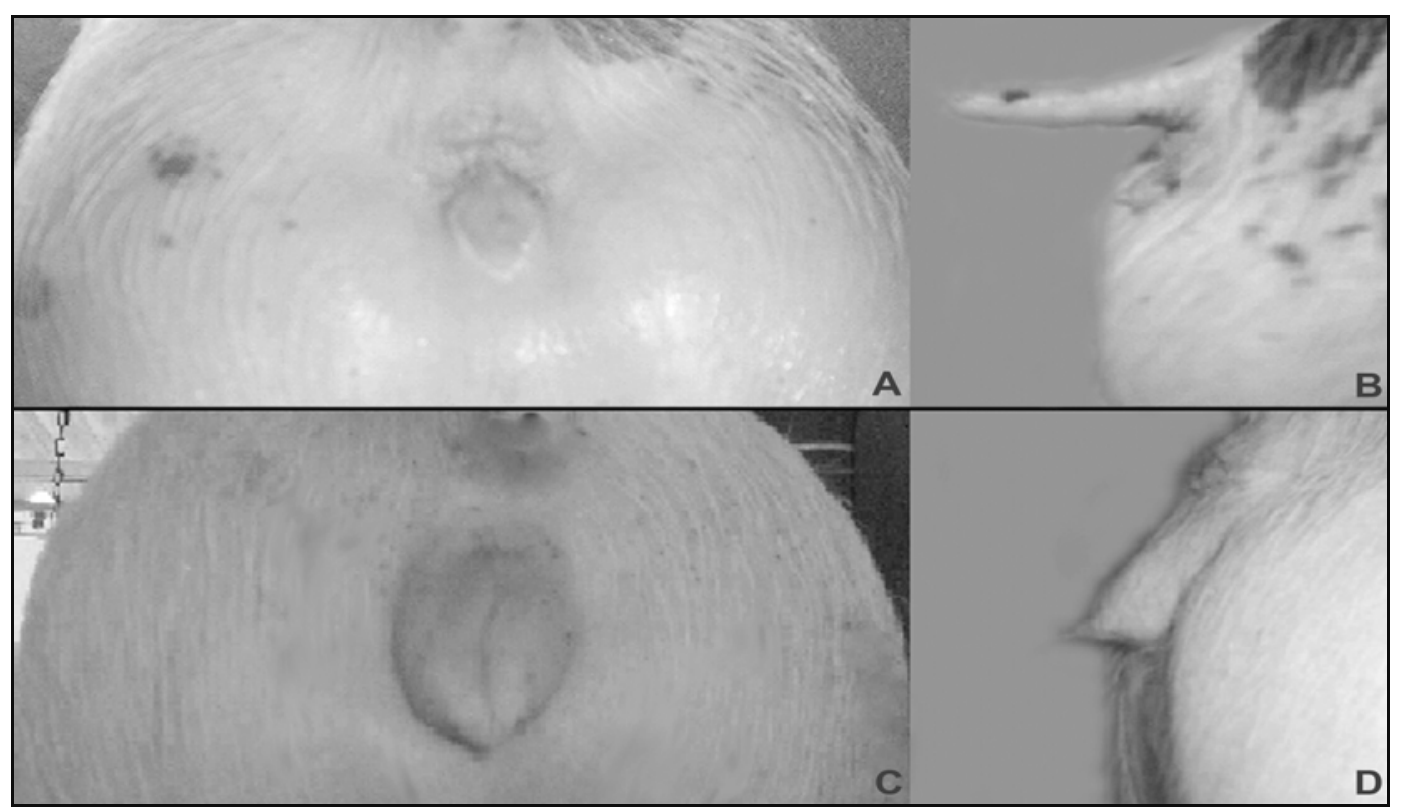

Figura 2. Visão posterior e lateral de leitoas alimentadas com dieta-controle (A e B) e dieta com $2 \mathrm{mg} \mathrm{kg}^{-1}$ de zearalenona (C e D) por 28 dias.

A ZEA é metabolizada no fígado principalmente em $\alpha$ e $\beta$-zearalenol. A competição da ZEA e de seus metabólitos com o 17 $\beta$-estradiol por receptores estrogênicos celulares explica os 
efeitos anabólicos e estrogênicos observados em diversas espécies (Diekman e Green, 1992). A ZEA apresenta maior potencial estrogênico comparada ao $17 \beta$-estradiol devido ao modo de ação e ao tempo de permanência no núcleo das células (Gaumy et al., 2001). Também há variação entre os produtos da biotransformação hepática da ZEA quanto ao efeito estrogênico, sendo o $\alpha$-zearalenol qualificado como de atividade mais intensa que a ZEA e o $\beta$ zearalenol (Cellius et al., 1999). Logo, a biotransformação hepática da ZEA em $\alpha$ zearalenol pode ser considerada uma etapa de ativação da toxina (Malekinejad et al., 2005). A produção predominante de $\alpha$-zearalenol em suínos, associada à maior afinidade desse metabólito pelos receptores estrogênicos, justifica a alta sensibilidade da espécie à micotoxina (Malekinejad et al., 2006).

\section{CONCLUSÕES}

O consumo de ração, a conversão alimentar, o ganho de peso e o peso vivo de leitoas prépúberes em fase de creche não são alterados com a adição de $2 \mathrm{mg} \mathrm{kg}^{-1}$ de zearalenona nas dietas. A zearalenona não altera os pesos relativos e absolutos de coração, fígado, rins e baço, mas aumenta o peso e o comprimento do trato reprodutivo e o volume vulvar em leitoas prépúberes.

\section{AGRADECIMENTOS}

Ao Conselho Nacional para o Desenvolvimento Científico e Tecnológico (CNPq), pela concessão de bolsas de iniciação científica a Ines Andretta e de mestrado a Luciano Hauschild. À Pró-Reitoria de Assuntos Estudantis (PRAE/UFSM), pela concessão de bolsa de trabalho a Eloiza Lanferdini e de monitoria a Neimar Cavazini. Aos graduandos Bruno Fraga, Cheila Lehnen, Everton Daniel, Guilherme dos Santos, Marco Antônio Kunrath, Renato Noal e Robson Pietro, pelo auxílio no trabalho de campo.

\section{REFERÊNCIAS BIBLIOGRÁFICAS}

ABID-ESSEFI, S.; OUANES, Z.; HASSEN, W. et al. Cytotoxicity, inhibition of DNA and protein syntheses and oxidative damage in cultures cells exposed to zearalenone. Toxicol. In Vitro, v.18, p.467-474, 2004.
BAUER, J., HEINRITZI, K.; GAREIS, M. et al. Changes in the genital tract of female swine after feeding with practice-relevant amounts of zearalenone. Tierarztl Prax, v.15, p.33-36, 1987.

CELliUS, T., HAUGEN, T.; GROTMOL, T. et al. A sensitive zonagenetic assay for rapid in vitro assesment of oestrogenic potency of xenobiotics and mycotoxins. Environ. Health Pers., v.40, p.1260-1267, 1999.

DIEKMAN, M.A., GREEN, M.L. Mycotoxins and reproduction in domestic livestock. J. Anim. Sci., v.70, p.1615-1627, 1992.

DOLL, S., DANICKE, S.; SCHNURRBUSCH, $\mathrm{U}$. The effect of increasing concentrations of Fusarium toxins in piglet diets on histological parameters of the uterus and vagina. Arch. Anim. Nutr., v.58, p.413-417, 2004.

DOLL, S., GERICKE, S.; DANICKE, S. et al. The efficacy of a modified aluminosilicate as a detoxifying agent in Fusarium toxin contaminated maize containing diets for piglets. J. Anim. Physiol. Anim. Nutr., v.89, p.342-358, 2005.

GAUMY, J.L., BAILLY, J.D.; BURGAT, V. et al. Zéaralénone: propriétés et toxicité expérimentale. Revue Méd. Vét., v.152, p.219234, 2001.

GREEN, M.L., DIEKMAN, M.A.; MALAYER, J.R. et al. Effect of prepubertal consumption of zearalenone on puberty and subsequent reproduction of gilts. J. Anim. Sci., v.68, p.171178, 1990.

HAUSCHILD, L., LOVATTO, P.A.; LEHNEN, C.R. et al. Digestibilidade e metabolismo de dietas de suínos contendo zearalenona com adição de organoaluminossilicato. Pesq. Agrop. Bras., v.42, p.219-224, 2007.

KUIPER-GOODMAN, T., SCOTT, P.M.; WATANABE, H. Risk assessment of the mycotoxin zearalenone. Regul. Toxicol. Pharmacol., v.7, p.253-306, 1987.

MACKENZIE, J.; GOLDMAN, R.N. The Student Edition of Minitab for Windows. Belmont: Addison-Wesley Longman, 1999. (Manual: Release 12.I.S.).

MALEKINEJAD， H., MAAS-BAKKER， R.; FINK-GREMMELS, J. Species differences in the hepatic biotransformation of zearalenone. Vet. J., v.172, p.96-102, 2006. 
MALEKINEJAD, H.; MAAS-BAKKER, R.F.; FINK-GREMMELS, J. Bioactivation of zearalenone by porcine hepatic biotransformation. Vet. Res., v.36, p.799-810, 2005.

NOGOWSKI, L. Effect of the myco-oestrogen zearalenone on carbohydrate and lipid metabolism indices in ovariectomized female rats. Possible role of insulin and its receptor. $J$. Anim. Physiol. Anim. Nutr., v.75, p.156-163, 1996.

NUTRIENT requirements of swine. Washington: National Academy of Science, 1998.

PLACINTA, C.M.; D'MELLO, J.P.F.; MACDONALD, A.M.C. A review of worldwide contamination of cereal grains and animal feed with Fusarium mycotoxins. Anim. Feed Sci. Technol., v.78, p.21-37, 1999.

RAINEY, M.R.; TUBBS, R.C.; BENNETT, L.W. et al. Prepubertal exposure to dietary zearalenone alters hypothalamo-hypophysial function but does not impair postpubertal reproductive function of gilts. J. Anim. Sci., v.68, p.2015-2022, 1990.

RAMOS, A.J.; HERNANDEZ, E.; PLADELFINA, J.M. et al. Intestinal absorption of zearalenone and in vitro study of non-nutritive sorbent materials. Int. J. Pharm., v.128, p.129$137,1996$.

SZKUDELSKA, K. Daidzein, coumestrol and zearalenone affect lipogenesis and lipolysis in rat adipocytes. Phytomedicine, v.9, p.338-345, 2002. 